\title{
Mutation of isocitrate dehydrogenase 1 induces glioma cell proliferation via nuclear factor- $\kappa B$ activation in a hypoxia-inducible factor $1-\alpha$ dependent manner
}

\author{
GUOLIANG WANG ${ }^{1}$, KE SAI $^{2}$, FANGHE GONG $^{1}$, QUNYING YANG ${ }^{2}$, FURONG CHEN $^{2}$ and JIAN LIN ${ }^{1}$ \\ ${ }^{1}$ Department of Neurosurgery, General Hospital of Guangzhou Military Commanding, Guangzhou, \\ Guangdong 510010; ${ }^{2}$ The State Key Laboratory of Oncology in South China, Department of Neurosurgery, \\ Sun Yat-Sen University Cancer Center, Guangzhou, Guangdong 510060, P.R. China
}

Received June 28, 2013; Accepted February 13, 2014

DOI: $10.3892 / \mathrm{mmr} .2014 .2052$

\begin{abstract}
Recently, mutations of the isocitrate dehydrogenase (IDH) 1 gene, which specifically occur in the majority of low-grade and secondary high-grade gliomas, have drawn particular attention of neuro-oncologists. Mutations of the IDH1 gene have been proposed to have significant roles in the tumorigenesis, progression and prognosis of gliomas. However, the molecular mechanism of the role of IDH1 mutants in gliomagenesis remains to be elucidated. The present study, showed that forced expression of an IDH1 mutant, of which the 132th amino acid residue arginine is substituted by histidine $\left(\mathrm{IDH} 1^{\mathrm{R} 132 \mathrm{H}}\right)$, promoted cell proliferation in cultured cells, while wild-type IDH1 overexpression had no effect on cell proliferation. Consistent with previous studies, it was also observed that expression of hypoxia-inducible factor $1-\alpha$ (HIF1- $\alpha$ ) was upregulated in IDH1 ${ }^{\mathrm{R} 132 \mathrm{H}}$ expressing cells with the induction of vascular endothelial growth factor (VEGF) expression. However, knockdown of VEGF via small RNA interference had no significant influence on the cell proliferation induced by overexpression of IDH1 ${ }^{\mathrm{R} 132 \mathrm{H}}$, implying that another signaling pathway may be involved. Next, forced expression of IDH1 ${ }^{\mathrm{R} 132 \mathrm{H}}$ was found to activate nuclear factor $-\kappa \mathrm{B}(\mathrm{NF}-\kappa \mathrm{B})$, since the inhibitory I $\kappa \mathrm{B}$ protein $(\mathrm{I} \kappa \mathrm{B} \alpha$ ) was highly phosphorylated and the $N F-\kappa B$ p65 subunit was translocated into the nucleus. Notably, knockdown of HIF1- $\alpha$ significantly blocked NF- $\kappa$ B
\end{abstract}

Correspondence to: Dr GuoLiang Wang, Department of Neurosurgery, General Hospital of Guangzhou Military Commanding, 111 Liuhua Road, Guangzhou, Guangdong 510010, P.R. China

E-mail: guolwang@163.com

Abbreviations: IDH, isocitrate dehydrogenase; HIF1- $\alpha$, hypoxia-inducible factor 1- $\alpha$; VEGF, vascular endothelial growth

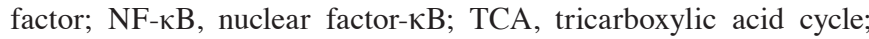
$\alpha$-KG, $\alpha$-ketoglutarate; 2-HG, 2-hydroxyglutarate

Key words: isocitrate dehydrogenase 1, hypoxia inducible factor $1-\alpha$, nuclear factor- $\kappa \mathrm{B}$, glioma, cell proliferation activation, which was induced by the overexpression of IDH1 mutants. In addition, expression of IDH1 mutants markedly induced the NF- $\mathrm{B}$ target gene expression, including cyclin $\mathrm{D} 1$ and $\mathrm{E}$ and $\mathrm{c}-\mathrm{myc}$, which were involved in the regulation of cell proliferation. In conclusion, it was demonstrated that the IDH1 mutant activated NF- $\kappa$ B in a HIF1- $\alpha$-dependent manner and was involved in the regulation of cell proliferation.

\section{Introduction}

Mutations of the enzyme cytosolic isocitrate dehydrogenase (IDH) 1 in gliomas, initially identified in 2008 (1), have drawn particular attention of neuro-oncologists in recent years. It has been demonstrated that mutations of IDH1 occur in $\sim 80 \%$ of grade II and III gliomas and secondary glioblastomas in humans (2-4). IDH1 mutations show high specificity in gliomas, but are rarely found in other types of human cancers (5). Thus, mutations of IDH1 have been proposed to have important roles in the tumorigenesis, progression and prognosis of gliomas.

The family of IDHs consists of three catalytic isozymes: IDH1, IDH2 and IDH3 (6). IDH is a critical enzyme in the tricarboxylic acid cycle (TCA) which catalyzes isocitrate (ICT) into $\alpha$-ketoglutarate $(\alpha-\mathrm{KG})$ in a nicotinamide adenine dinucleotide phosphate $\left(\mathrm{NADP}^{+}\right)$-dependent manner (IDH1 and IDH2) or nicotinamide adenine dinucleotide $\left(\mathrm{NAD}^{+}\right)$-dependent manner (IDH3). A mutation has been found in the gene, which leads to substitution of the 132nd amino acid residue (an arginine) of IDH1 by a histidine (R132H); this has been found to account for $\sim 90 \%$ of all IDH1 mutations, with other mutations including substitution at this codon for cysteine (R132C), glycine $(\mathrm{R} 132 \mathrm{G})$, leucine $(\mathrm{R} 132 \mathrm{~L})$ or serine (R132S) $(4,7,8)$. The substituted R132 is essential for enzymatic activity, and is contained within an evolutionary highly conserved region located at the binding site for ICT (1). More recently, mutations of IDH2 were also identified in a group of gliomas at a low frequency (4). It is intriguing that R172 in IDH2, which is the analogous site to R132 in IDH1, is also the major mutation site of IDH2 in gliomas (4). Notably, mutations of IDH1 and IDH2 are mutually exclusive in gliomas, implying that the outcome of the IDH1 or IDH2 mutations may be equivalent (5). 
Functional studies of IDH1 mutations have demonstrated that mutant IDH1 blocks the enzymatic activity and results in decreased $\alpha$-KG levels (9); however, a gain of neomorphic activity at high levels of 2-hydroxyglutarate $(2-\mathrm{HG})$ is observed (10). The high levels of 2-HG have been indicated to have potential value for the clinical diagnosis and treatment of gliomas (11). However, the manner by which IDH1 mutants are involved in tumorigenesis remains to be elucidated. One of the explored mechanisms of mutant IDH1 in the regulation of tumorigenesis is the upregulation of hypoxia-inducible factor 1- $\alpha$ (HIF1- $\alpha$ ) (9). HIF1- $\alpha$ has a critical role in cells under hypoxic conditions, which activates numerous genes that are involved in multiple cellular processes, including cell proliferation and survival, metastasis and angiogenesis, predominantly via the vascular endothelial growth factor (VEGF) $(9,12,13)$. Under normal circumstances, HIF1- $\alpha$ was continuously degraded by prolyl hydroxylase (PHD) which is dependent on $\alpha-K G$. Thus, decreased $\alpha-K G$ levels downregulate the activity of $\mathrm{PHD}$, resulting in the stabilization and accumulation of HIF1- $\alpha$ and the subsequent activation of the HIF signaling pathway. It is noteworthy that gene expression that was expected to be induced by HIF1- $\alpha$ was not observed in patients with acute myeloid leukemia harboring IDH1 mutations (14). It is possible that multiple cellular signaling pathways are involved in cells with IDH1 mutations.

Various studies have demonstrated that cellular hypoxia and HIF signal activation are associated with the nuclear factor $-\kappa \mathrm{B}(\mathrm{NF}-\kappa \mathrm{B})$ transcription factor activation (15-17). In 1994, hypoxia was found to induce the activation of $\mathrm{NF}-\kappa \mathrm{B}(18)$; however, the underlying mechanism remains to be identified $(19,20)$. $N F-\kappa B$, which is tightly controlled, regulates a wide range of cellular processes and is extensively involved in various cancer types, including gliomas (21). Normally, $\mathrm{NF}-\kappa \mathrm{B}$ binding to inhibitory I $\mathrm{B}$ proteins is inactivated in the cytoplasm (22). Thus, translocation of $\mathrm{NF}_{-} \kappa \mathrm{B}$ to the nucleus under dysregulation is involved in numerous diseases $(23,24)$. $\mathrm{NF}-\kappa \mathrm{B}$ has also been demonstrated to be a critical regulator in tumorigenesis and to be involved in cell survival, metastasis and angiogenesis (22). Considering the parallel roles of the two transcription factors in tumorigenesis, it remains to be elucidated whether there is a correlation in tumorigenesis.

The present study investigated the role of IDH1 ${ }^{\mathrm{R} 132 \mathrm{H}}$ expression on cell proliferation in glioma cells and the potential underlying mechanism.

\section{Materials and methods}

Cell lines and cell culture. Human SVGp12 normal astrocyte and U251 glioma cell lines were obtained from American Type Culture Collection (ATCC, Manassas, VA, USA). All the cells were maintained as per standard protocols. Briefly, the cells were cultured in Dulbecco's modified Eagle medium (DMEM; Invitrogen Life Technologies, Carlsbad, CA, USA) with $10 \%$ of fetal bovine serum. Penicillin $(100 \mathrm{U} / \mathrm{ml})$, streptomycin $(100 \mu \mathrm{g} / \mathrm{ml})$ and L-glutamate (2 mM) (Sangon, Shanghai, China) were added. All the cells were cultured at $37^{\circ} \mathrm{C}$ in an incubator (Life Technologies, Baltimore, MD, USA) containing 5\% $\mathrm{CO}_{2}$.

Cloning, site-directed mutagenesis and expression vector construction of IDH1. The total RNA was extracted from cultured U251 glioma cells using TRIzol ${ }^{\circledR}$ reagent (Invitrogen Life Technologies) according to the manufacturer's instructions. Up to $5 \mu \mathrm{g}$ of total RNA was reverse-transcribed into cDNA using Moloney murine leukemia virus (M-MLV) reverse transcriptase (Clontech, Palo Alto, CA, USA). The cDNAs were used as templates for the amplification of wild-type IDH1 using two primers (forward, 5'-atgtccagaaaaatccatggcggttctg-3' and reverse, 5'-ttaaagtttggcctgagctagtttggcettc- $3^{\prime}$ ), according to the open reading frame of the IDH1 cDNA sequence (GenBank accession no. NM_031510.1). The specific site-directed mutagenesis primers (forward, 5'-ctatcatcataggtcatcatgcttatggggatc-3' and reverse, 5'-gatcccataagcatgatgacctatgatgatag-3') were used to amplify the cDNA sequence of mutated IDH $1^{\mathrm{R} 132 \mathrm{H}}$ with the wild-type IDH1 cDNA sequence as templates according to the protocols outlined in the Site-Directed Gene Mutagenesis kit (Beyotime Institute of Biotechnology, Shanghai, China). The obtained sequences were confirmed by DNA sequencing (Sangon, Shanghai, China) and the resultant fragments of wild-type and mutated IDH1 were sub-cloned into pCMV-Sport6 plasmid (Invitrogen, Carlsbad, CA, USA) with restriction sites NotI and XhoI.

Recombinant plasmids and small interfering RNA (siRNA) transfection. The cells were seeded in a six-well culture plate $\left(2 \times 10^{5}\right.$ cells/well) and incubated at $37^{\circ} \mathrm{C}$ with $5 \% \mathrm{CO}_{2}$ until the cells reached $80 \%$ confluence. Cell transfection was performed according to the manufacturer's instructions. Briefly, plasmid DNA $(1 \mu \mathrm{g})$ or siRNA (HIF-1 $\alpha$ siRNA sc-35561 and VEGF siRNA sc-29520, Santa Cruz Biotechnology, Inc., Santa Cruz, CA, USA) was diluted in $500 \mu 1$ of DMEM with $5 \mu 1$ Lipofectamine (Invitrogen), prior to being mixed and incubated at room temperature (RT) for $15 \mathrm{~min}$. The mixtures were then added to the cells resulting in a final volume of $3 \mathrm{ml}$ medium and incubated for the indicated times.

Nuclear protein extraction. The nuclear proteins were extracted using an extraction kit (Sangon, Shanghai, China) according to the manufacturer's instructions. Briefly, the cells were lysed in cytoplasmic buffer containing protease inhibitors, mixed and incubated for $15 \mathrm{~min}$ at $4^{\circ} \mathrm{C}$ followed by centrifugation at $13,400 \mathrm{x} \mathrm{g}$ for $20 \mathrm{~min}$ at $4^{\circ} \mathrm{C}$. The cell pellets were collected and resuspended in nucleus buffer (Ficoll 400 and protease inhibitor; Sangon, Shanghai, China) for $10 \mathrm{~min}$ at $4^{\circ} \mathrm{C}$. Next, the sample was centrifuged at $13,400 \mathrm{x}$ g for $10 \mathrm{~min}$ at $4^{\circ} \mathrm{C}$. The supernatant containing nuclear proteins was collected for analysis.

Western blot analysis. Proteins from cultured cells were collected and a total of 20-30 $\mu \mathrm{g}$ protein was fractionated by $12 \%$ SDS-PAGE and transferred to a nitrocellulose membrane (Amersham, Little Chalfont, UK). The membrane was treated using the following procedure by agitating and blocking at RT with $2 \%$ skimmed milk in Tris-buffered saline (TBS) for $1 \mathrm{~h}$ followed by incubation in primary antibodies $\left[\mathrm{IDH} 1^{\mathrm{R} 132 \mathrm{H}}\right.$ specific mouse monoclonal antibody IDH1-R132H mutant monoclonal antibody (IMab-1) (Dianova, Hamburg, Germany); mouse monoclonal HIF1- $\alpha$ antibody, mouse monoclonal VEGF antibody and rabbit polyclonal $\mathrm{NF}-\kappa \mathrm{B}$ p65 antibody (Santa Cruz Biotechnology, Inc.); mouse mono- 
clonal Iк $\mathrm{B} \alpha$ and $\mathrm{pI} \kappa \mathrm{B} \alpha$ antibody (Cell Signaling Technology, Boston, MA, USA)]. The solution was diluted in blocking buffer (2\% skimmed milk powder dissolved in TBS) at $4^{\circ} \mathrm{C}$ overnight and washed three times with TBS and Tween-20 (TBST; $10 \mathrm{mM}$ Tris-HCl, pH 7.5, $150 \mathrm{mM} \mathrm{NaCl}$, and $0.05 \%$ Tween-20) for 10 min each at RT. Subsequently, the membrane was incubated in peroxidase-conjugated secondary antibody (Boster Corporation, Wuhan, Hubei, China; diluted at 1:5,000 in blocking buffer) for $1 \mathrm{~h}$. Following washing three times with TBST and once with TBS each for $10 \mathrm{~min}, 1 \mathrm{ml}$ of 4-chloro-1-naphthol as a horse radish peroxidase substrate with $9 \mathrm{ml}$ of TBS and $6 \mu \mathrm{l}$ of $\mathrm{H}_{2} \mathrm{O}_{2}$ was used for visualizing the target protein in the dark for 5-30 min.

MTT assay. For the MTT assay, cells were planted in 96-well plates and cultured under regular conditions until they reached $80 \%$ confluency. The plasmid or siRNA was transfected according to the standard protocols, and were continually incubated with cells at $37^{\circ} \mathrm{C}$ with $5 \% \mathrm{CO}_{2}$ for $48 \mathrm{~h}$. Next, the culture medium was discarded and fresh medium containing MTT ( $5 \mathrm{mg} / \mathrm{ml}$ in PBS, $150 \mu \mathrm{l} /$ well, Sangon, Shanghai, China) and incubated with cells for an additional $4 \mathrm{~h}$. Next, $150 \mu \mathrm{l}$ of dimethyl sulfoxide (Sigma-Aldrich, St. Louis, MO, USA) was added per well, agitated gently for $10 \mathrm{~min}$ to dissolve the formazan, and the absorbance at $490 \mathrm{~nm}$ was determined by an ELISA reader (Bio-tek Instruments, Inc., Winooski, VT, USA). Each cell viability assay was performed in quadruplicate and repeated three times. The data are expressed as the mean \pm standard error of the mean and differences were analyzed by Student's t-test.

Quantitative polymerase chain reaction ( $q P C R)$ analysis. The total RNA was extracted from cultured cells using TRIzol reagent (Invitrogen Life Technologies) according to the manufacturer's instructions. Up to $5 \mu \mathrm{g}$ of total RNA was reverse-transcribed into cDNA using M-MLV reverse transcriptase (Clontech). The cDNAs were used as templates for qPCR. The primers were as follows: c-myc, forward, 5'-acacatcagcacaactacgc-3' and reverse, 5'-cctcttgacattctcctcggt-3'; cyclin D1, forward, 5'-gccaacctcctcaacgaccgg-3' and reverse, 5'-gtccatgttctgctgggectg-3'; cyclin E, forward, 5'-gtcctggctgaatgatacatgc-3' and reverse, 5'-ccctattttgttcagacaacatggc-3'; $\beta$-actin (forward, 5'-ctccatcctggcetcgctgt-3' and reverse, $5^{\prime}$-gctgtcaccttcaccgttcc-3') were used as the control. The qPCR mixture contained $5 \mu 1$ SsoFast ${ }^{\mathrm{TM}}$ EvaGreen Supermix (Bio-Rad, Hercules, CA, USA), $1 \mu 1$ of cDNA (diluted at 1:50) and $2 \mu \mathrm{l}$ of each of the forward and reverse primers $(1 \mu \mathrm{M})$ to a final volume of $10 \mu$ l. The PCR procedure was as follows: $94^{\circ} \mathrm{C}$ for $4 \mathrm{~min}, 94^{\circ} \mathrm{C}$ for $20 \mathrm{sec}, 55^{\circ} \mathrm{C}$ for $30 \mathrm{sec}$ and $72^{\circ} \mathrm{C}$ for $20 \mathrm{sec}$; $2 \mathrm{sec}$ for plate reading for 35 cycles; and a melting curve from 65 to $95^{\circ} \mathrm{C}$. $\beta$-actin was used as the control for normalizing gene expression. In total, three independent experiments were performed. The data obtained were calculated by the $2^{-\Delta \Delta \mathrm{Ct}}$ method and subjected to statistical analysis as previously described (25), followed by an unpaired sample t-test.

\section{Results}

Expression of IDHI ${ }^{R I 32 H}$ in glioma cells. To analyze the role of IDH1 mutations in glioma cells, human U251 glioma and

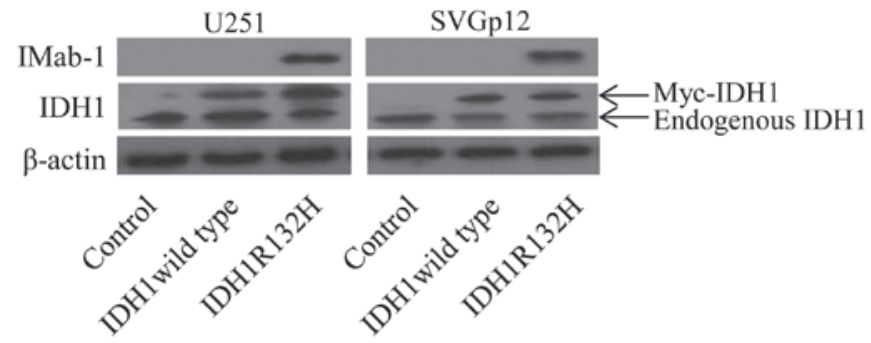

Figure 1. Establishment of cell lines transfected with expressing vectors. The cells were transfected with either control null vectors (control), vectors containing wild-type IDH1 (IDH1 wild-type) or vectors containing mutant IDH1 (IDH1 ${ }^{\mathrm{R} 132 \mathrm{H}}$ ). At $\sim 48 \mathrm{~h}$ after transfection, the cells were harvested and lysed to analyze IDH1 protein expression by western blot analysis. The IDH1 ${ }^{\mathrm{R} 132 \mathrm{H}}$ mutant specific antibody IMab-1 and IDH1 antibody, as indicated, were used to determine the protein level in cells. $\beta$-actin was used as a control. IMab-1, IDH1-R132H mutant monoclonal antibody; IDH1, isocitrate dehydrogenase 1 .

SVGp12 normal astrocyte cell lines transfected with vectors expressing the myc-tagged wild-type or R132H mutant of IDH1 were established. The cell lysates were assessed by for western blot analysis of IDH1 protein expression. In order to determine $\mathrm{IDH} 1^{\mathrm{R} 132 \mathrm{H}}$ protein levels specifically, the IDH $1^{\mathrm{R} 132 \mathrm{H}}$-specific monoclonal antibody IMab-1 was used. The results showed that $\mathrm{IDH}^{\mathrm{R} 132 \mathrm{H}}$ was only detected in cells transfected with $\mathrm{IDH} 1^{\mathrm{R} 132 \mathrm{H}}$ expression vectors (Fig. 1, upper panel). Furthermore, following incubation with IDH1 antibodies, two bands were detected in overexpressing, vector-transfected cells: The upper band denoted the myc-tagged IDH1 and the lower band denoted endogenous proteins of IDH1 (Fig. 1, middle panel). These results implied that the IDH1 $1^{\mathrm{R} 132 \mathrm{H}}$ mutant was successfully expressed in U251 and SVGp12 cells.

Expression of IDH $1^{\text {RI32H }}$ promotes cell proliferation. To investigate the role of forced expression of IDH $1^{\mathrm{R} 132 \mathrm{H}}$ in cell growth, the MTT assay was performed. The results showed that the expression of IDH1 $1^{\mathrm{R} 132 \mathrm{H}}$ significantly increased cell proliferation in U251 cells, while overexpression of IDH1 wild-type had no marked influence on cell proliferation (Fig. 2A). Similar results were also observed in SVGp12 cells (Fig. 2B). The data indicated that IDH1 mutants increased cell proliferation.

Knockdown of VEGF has no significant impact on cell proliferation induced by IDH1 ${ }^{R I 32 H}$ expression. HIF1- $\alpha$ augmentation in $\mathrm{IDH}^{\mathrm{R} 132 \mathrm{H}}$-expressing cells has been shown to be involved in tumor growth, which was associated with VEGF (9). To clarify whether IDH1 ${ }^{\mathrm{R} 132 \mathrm{H}}$ promotes cell proliferation via HIF1- $\alpha$-induced VEGF expression, VEGF RNA interference or transfection with IDH1 expressing vector was performed in U251 glioma cells (Fig. 3). Western blot analysis showed that the expression of IDH1 $1^{\mathrm{R} 132 \mathrm{H}}$ significantly increased HIF1- $\alpha$ protein levels in U251 glioma cells. The results also demonstrated that expression of IDH $1^{\mathrm{R} 132 \mathrm{H}}$ upregulated VEGF expression, causing a high cell proliferation rate. Notably, cell proliferation was not markedly affected when VEGF was knocked down, which implies that IDH1 ${ }^{\mathrm{R} 132 \mathrm{H}}$-induced cell proliferation may be involved in multiple signaling pathways (Fig. 3). Similar results were obtained using SVGp12 cells (data not shown). 


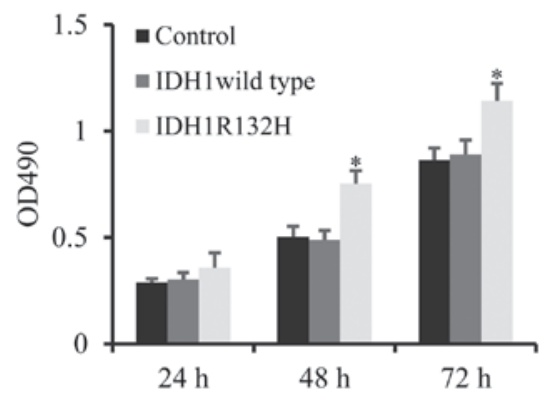

SVGp12

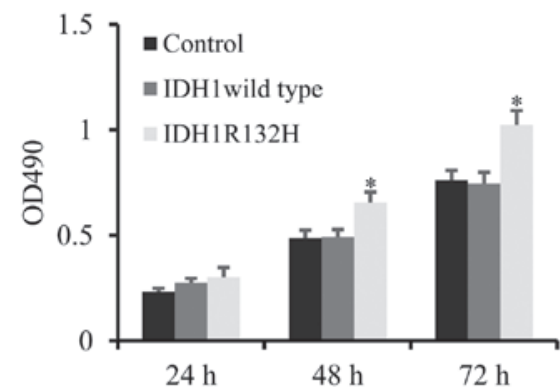

Figure 2. Effect of IDH1 ${ }^{\mathrm{R} 132 \mathrm{H}}$ expression on cell proliferation analyzed by MTT assay. Cell proliferation was determined in (A) U251 and (B) SVGp12 cells after the vectors were transfected for 24,48 and $72 \mathrm{~h}$. The experiments were performed in quadruplicate and repeated three times. The absorbance at $490 \mathrm{~nm}$ was determined by an ELISA reader. Data are expressed as the mean \pm standard error and differences were analyzed by Student's-t test. " $\mathrm{P}<0.05$ vs. control or wild-type transfected cells denotes significant differences. IDH1, isocitrate dehydrogenase 1; OD490, optical density at $490 \mathrm{~nm}$.

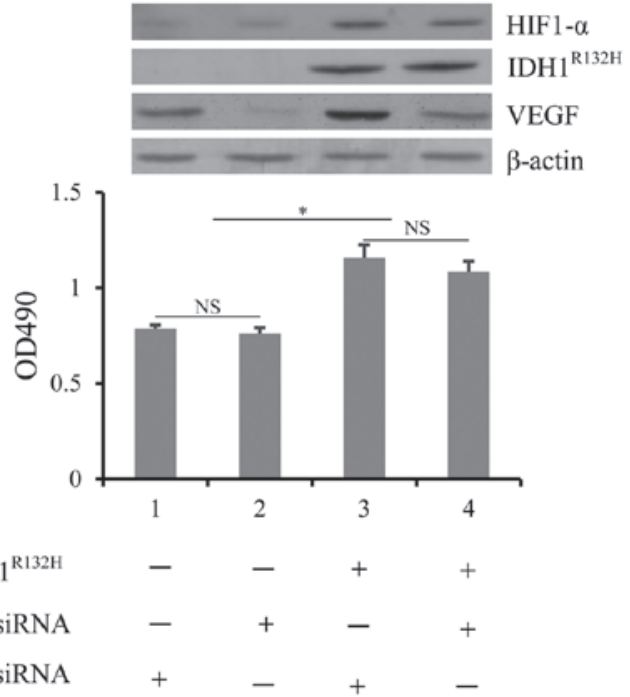

Figure 3. Effect of transfection of IDH1 ${ }^{\mathrm{R} 132 \mathrm{H}}$ expressing vectors and VEGF RNA interference on cell proliferation. At $\sim 72 \mathrm{~h}, \mathrm{U} 251$ cells transfected with expressing vectors or incubated with siRNA were harvested for analysis. Western blot analysis was used to determine the protein levels of HIF1- $\alpha$, $\mathrm{IDH} 1^{\mathrm{R} 132 \mathrm{H}}$ and VEGF in differently treated cell groups. $\beta$-actin was used as a control. Cell proliferation of different transfected cells was detected by an MTT assay. Scramble siRNA was used as a non-specific control. NS indicates that there is no statistical significance, ${ }^{*} \mathrm{P}<0.05$ denotes significant differences. VEGF, vascular endothelial growth factor; IDH1, isocitrate dehydrogenase 1; HIF1- $\alpha$, hypoxia-inducible factor 1- $\alpha$; siRNA, small interfering RNA; OD490, optical density at $490 \mathrm{~nm}$.

Expression of IDH $1^{R I 32 H}$ promotes $\mathrm{NF}-\kappa B$ nuclear translocation and I $\kappa B \alpha$ phosphorylation. In order to assess whether NF- $\kappa \mathrm{B}$ was activated in IDH $1^{\mathrm{R} 132 \mathrm{H}}$ expressing cells, the NF- $\mathrm{kB}$ signaling pathway was investigated in transfected cells. It is known that

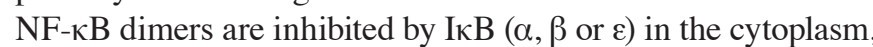

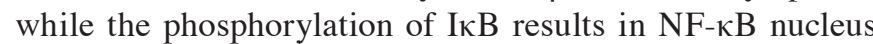
translocation and activation (22). Thus, the phosphorylation state of IкB in IDH1 $1^{\mathrm{R} 132 \mathrm{H}}$ expressing U251 cells was assessed. The results revealed that the expression of $\mathrm{IDH} 1^{\mathrm{R} 132 \mathrm{H}}$ promoted the phosphorylation of $\mathrm{I} \mathrm{K} \mathrm{B} \alpha$, implying that $\mathrm{I} \kappa \mathrm{B} \alpha$ was released from NF-kB (Fig. 4, upper left panels). In addition, in order to define whether NF- $\kappa B$ nuclear translocation is increased upon $\mathrm{IDH} 1^{\mathrm{R} 132 \mathrm{H}}$ expression, the levels of $\mathrm{p} 65$ protein, which is one subunit of NF- $\mathrm{KB}$, were detected in the nucleus. As expected,

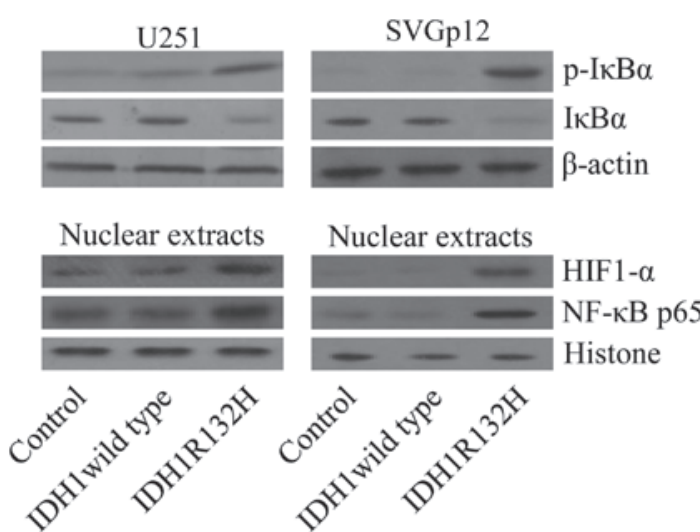

Figure 4. Effect of IDH1 ${ }^{\mathrm{R} 132 \mathrm{H}}$ on NF- $\mathrm{kB}$ activation. The total cell or nuclear extracts were prepared after $72 \mathrm{~h}$ of vector transfection. The phosphorylated IкB and IкB protein levels in U251 (upper left panels) or SVGp12 cells (upper right panels) were determined by western blot analysis with the indicated antibodies. $\beta$-actin was used as a control. The protein levels of HIF1- $\alpha$ and NF-kB p65 in the nucleus in U251 (lower left panels) or SVGp12 cells (lower right panels) are shown. Histone was used as a control of nuclear proteins. IDH1, isocitrate dehydrogenase $1 ; \mathrm{NF}-\kappa \mathrm{B}$, nuclear factor- $\kappa \mathrm{B}$; HIF1- $\alpha$, hypoxia-inducible factor $1-\alpha$; IкB, inhibitor of NF- $\mathrm{KB}$.

the NF- $\kappa B$ p65 protein levels were increased in nuclear extracts, as was HIF1- $\alpha$ (Fig. 4, lower left panel). The same effects of overexpression of $\mathrm{IDH} 1^{\mathrm{R} 132 \mathrm{H}}$ on NF- $\mathrm{KB}$ were observed in SVGp1 2 cells (Fig. 4, right panels). These results indicated that expression of IDH $1^{\mathrm{R} 132 \mathrm{H}}$ promoted $\mathrm{NF}-\mathrm{\kappa B}$ activation.

Knockdown of HIF1- $\alpha$ blocks NF- $\kappa B$ activation induced by expression of $I D H 1^{R l 32 H}$. In order to confirm whether NF- $\mathrm{BB}$ activation was dependent on HIF1- $\alpha$, HIF-1 $\alpha$ RNA silencing in combination with transfection with a vector expressing IDH1 ${ }^{\mathrm{R} 132 \mathrm{H}}$ was performed in cells. At $\sim 72 \mathrm{~h}$ post transfection, the cells were harvested and nuclear proteins were extracted and subjected to western blot analysis. In the U251 and SVGp1 2 cell lines, knockdown of HIF-1 $\alpha$ significantly blocked NF- $\kappa \mathrm{B}$ p65 nuclear translocation induced by expression of $\mathrm{IDH}^{\mathrm{R} 132 \mathrm{H}}$ (Fig. 5), implying that NF- $\mathrm{kB}$ activation occurred in a HIF1- $\alpha$-dependent manner.

$I D H 1^{R I 32 H}$ promotes cell proliferation through cyclin DI and $E$ and c-myc activated by $N F-\kappa B$. Various studies have demon- 

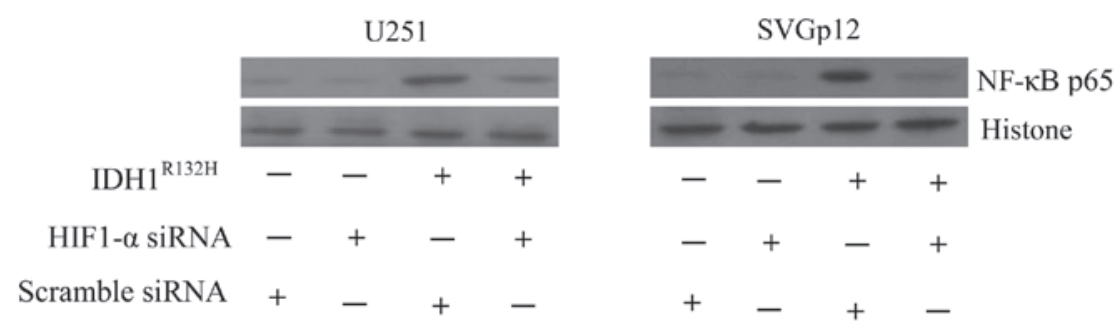

Figure 5. Effect of HIF1- $\alpha$ siRNA on NF- $\kappa$ B nucleus translocation. IDH1 ${ }^{\mathrm{R} 132 \mathrm{H}}$ expression vectors or HIF1- $\alpha$ siRNA were transfected in cells. Scramble siRNA was used as a non-specific control. The nuclear extracts were prepared $72 \mathrm{~h}$ post transfection, and protein levels of NF- $\kappa \mathrm{B}$ p 65 in the nucleus were determined by western blot analysis in U251 (left panels) or SVGp12 cells (right panels). Histone was used as a control of nuclear proteins. HIF1- $\alpha$, hypoxia-inducible factor $1-\alpha$; NF- $\kappa$, nuclear factor- $\kappa \mathrm{B}$; siRNA, small interfering RNA.

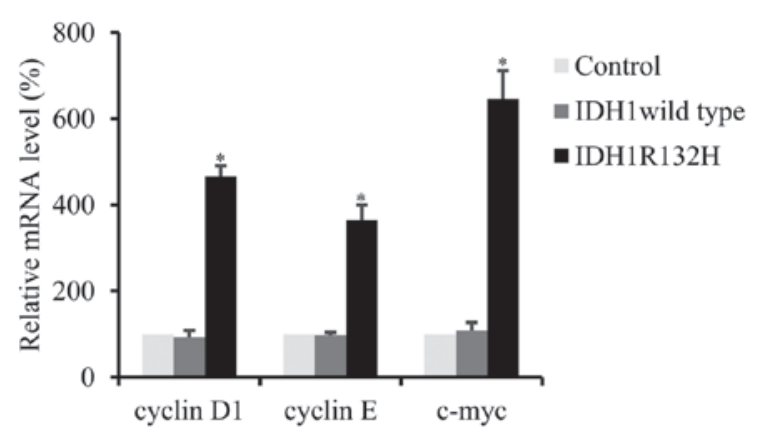

Figure 6. Effect of IDH1 ${ }^{\mathrm{R} 132 \mathrm{H}}$ on NF-кB target gene expression. Transcription levels of cyclin D1 and E and c-myc were analyzed by quantitative polymerase chain reaction in transfected U251 cells. $\beta$-actin was used as a loading control. All the experiments were independently performed at least three times The data are expressed as the mean \pm standard error and analyzed using Student's t-test, and ${ }^{*} \mathrm{P}<0.05$ was considered statistically significant. IDH1, isocitrate dehydrogenase $1 ; \mathrm{NF}-\kappa \mathrm{B}$, nuclear factor- $\kappa \mathrm{B}$.

strated that $\mathrm{NF}-\kappa \mathrm{B}$ is involved in the regulation of cell proliferation through cyclin D1 and E and c-myc (26-28). In order to further define whether expression of IDH1 ${ }^{\mathrm{R} 132 \mathrm{H}}$ was involved in NF- $\mathrm{B}$-mediated cell proliferation, the transcription levels of cyclin D1 and E and c-myc were determined by qPCR. IDH1 ${ }^{\mathrm{R} 132 \mathrm{H}}$, as opposed to wild-type IDH1, significantly induced the expression of cyclin D1 and E and c-myc in U251 cells (Fig. 6). Furthermore, increased expression levels of cyclin D1, cyclin E and c-myc were also observed in IDH1 ${ }^{\mathrm{R} 132 \mathrm{H}}$ expressing SVGp12 cells (data not shown).

\section{Discussion}

The IDH1 gene is specifically mutated in gliomas, including astrocytomas, oligodendrogliomas or oligoastrocytomas of grades II and III and secondary glioblastomas, with an occurrence of $\sim 80 \%$; mutations in this gene seldomly occur in primary glioblastomas or other types of human gliomas (29). Mutation of IDH1 has been identified as an early event in tumorigenesis, indicating that it has critical roles in the evolutionary development of gliomas $(3,4)$. However, the molecular mechanism of IDH1 mutants underlying the development and progression of tumors remains to be elucidated.

In 2009, Zhao et al (9) first reported that the IDH1 mutation contributed to tumorigenesis through the induction of HIF1- $\alpha$. In this study, overexpression of IDH1 mutants in cultured cells suppressed the activity of wild-type IDH1 via the formation of heterodimers, resulting in a decrease of the enzyme product, $\alpha-K G$. $\alpha-K G$ is essential for PHD, which promotes HIF1- $\alpha$ degradation. Thus, forced expression of the IDH1 mutant activated the HIF1- $\alpha$ signal and subsequently targeted gene expression, including that of glucose transporter 1, VEGF and phosphoglycerate kinase 1. Another study demonstrated that IDH1 mutants acquired neomorphic activity that catalyzed $\alpha-\mathrm{KG}$ to $2-\mathrm{HG}$ and resulted in an accumulation of $2-\mathrm{HG}$ that led to tumor formation and malignancy (10). In accordance with a previous study, the present study identified that forced expression of IDH1 $1^{\mathrm{R} 132 \mathrm{H}}$ mutants in cells increased HIF1- $\alpha$ and cell proliferation. Furthermore, it was also shown that IDH1 $1^{\mathrm{R} 132 \mathrm{H}}$ activated the $\mathrm{NF}-\kappa \mathrm{B}$ signaling pathway, which is frequently dysregulated in cancers (30).

In the present study, it was demonstrated that the knockdown of VEGF, the HIF1- $\alpha$ target gene, notably contributed to angiogenesis in tumorigenesis, and did not affect the cell proliferation evoked by expression of the IDH1 mutant. Thus, it was hypothesized that the IDH1 mutant may activate other signaling pathways dependent on HIF1- $\alpha$. As expected, it was shown that forced expression of IDH1 mutants activated NF- $\kappa \mathrm{B}$ in a HIF1- $\alpha$ dependent manner. The crosstalk between HIF $1-\alpha$ and NF- $\kappa$ B has been previously reported (15). HIF1- $\alpha$ was indicated to promote inflammation of the local stromal microenvironment via NF- $\kappa \mathrm{B}$, which was in favor of tumor cell growth and metastasis (31). NF- $\kappa \mathrm{B}$ was demonstrated to be a downstream effector of the HIF1- $\alpha$-dependent response, which was involved in the regulation of neutrophil survival (16). Expression of IDH1 ${ }^{\mathrm{R} 132 \mathrm{H}}$ promoted the phosphorylation of $\mathrm{I} \kappa \mathrm{B} \alpha$ and resulted in the release of $\mathrm{NF}-\kappa \mathrm{B}$, which subsequently accumulated and translocated into the nucleus. However, there were limitations to the present study: The manner by which HIF1- $\alpha$ regulates NF- $\kappa \mathrm{B}$ activation was not defined. Whether molecular events between HIF1- $\alpha$ and $\mathrm{NF}-\kappa \mathrm{B}$ activation exist requires further investigation. Previously, it has been proposed that the oxygen-sensing hydroxylases which regulate the HIF pathway may also be involved in the regulation of significant components of the $\mathrm{NF}-\kappa \mathrm{B}$ pathway $(32,33)$.

It has been reported that the activation of $\mathrm{NF}-\kappa \mathrm{B}$ is tightly controlled. Normally, NF- $\kappa \mathrm{B}$ is inhibited by $\mathrm{I} \kappa \mathrm{B}$, which is able to be phosphorylated by the $\mathrm{I} \kappa \mathrm{B}$ kinase complex, resulting in $N F-\kappa B$ liberation and activation $(34,35)$. NF- $\kappa B$ is activated in a wide range of cancers and activates various genes involved in tumorigenesis processes, including cell survival, apoptosis, 
angiogenesis and metastasis (21). One of the significant features of $\mathrm{NF}-\kappa \mathrm{B}$ with regard to gliomas is the regulation of cellular proliferation. Oncogenes including cyclin D1 and $\mathrm{E}$, and c-myc have been reported to be activated by $\mathrm{NF}-\kappa \mathrm{B}$. High levels of cyclin D1 and E were found in the majority of glioblastomas, and cyclin D1 was closely correlated to cell proliferation and to the progression of tumors (36-38). c-myc is a critical transcription factor, which induces numerous cyclins and CDK proteins and is highly elevated in tumors $(39,40)$. In the present study, it was demonstrated that expression of IDH1 mutants activated NF- $\mathrm{B}$ and induced high expression levels of cyclin D1 and E, and c-myc in cultured cells. Thus, it was deduced that IDH1 $1^{\mathrm{R} 132 \mathrm{H}}$ promoted cell proliferation not only via HIF1- $\alpha$-induced VEGF activation, but also by HIF1- $\alpha$-induced NF- $\kappa$ B activation.

It is of note that patients with IDH1 mutations have an improved prognosis compared to those harboring wild-type IDH1 (1,41). In addition, the IDH1 mutants showed high sensitivity to chemotherapeutics $(42,43)$. It is indicated that the IDH1 mutations not only reduce the activity of NADPH generation, but also consume NADPH, thus leading to an increase in oxidative stress and oxidative DNA damage $(10,44)$. This may explain why glioma cells harboring IDH1 mutations have a high sensitivity to chemotherapy and patients with IDH1 mutations have longer survival times compared with patients harboring wild-type IDH1.

Collectively, the mutant IDH1 is involved in tumorigenesis through the induction of HIF1- $\alpha$. On the other hand, IDH1 sensitizes tumor cells to chemotherapy via an increase in cellular oxidative stress. In the present study, it was demonstrated that the forced expression of IDH1 mutants promoted the proliferation of glioma cells via the activation of NF- $\kappa \mathrm{B}$ in a HIF1- $\alpha$ dependent manner. The present study provided new insights into the IDH1 mutation in the regulation of tumorigenesis. Since the results of the present study showed that IDH1 mutants are oncogenic, it requires to be further determined whether targeting IDH1 mutations is helpful for glioma therapy. More recently, a selective inhibitor (AGI-5198) of DHI1 ${ }^{\mathrm{R} 132 \mathrm{H}}$ has been developed by Rohle et al (45), which suppresses the production of 2-HG as well as colony formation. In particular, this inhibitor had no effect on wild-type IDH1. This inhibitor also decreased the proliferation of IDH1 glioma xenografts, while not affecting apoptosis, implying that targeting IDH1 mutations may reverse the dysregulation of cell growth and may be beneficial for gliomas. However, the precise molecular pathogenesis of IDH1 mutants in gliomas requires further investigation.

\section{Acknowledgements}

This study was supported by the Science and Technology Planning Project of Guangdong Province, China (2011B031800186).

\section{References}

1. Parsons DW, Jones S, Zhang X, et al: An integrated genomic analysis of human glioblastoma multiforme. Science 321 : 1807-1812, 2008.

2. Balss J, Meyer J, Mueller W, et al: Analysis of the IDH1 codon 132 mutation in brain tumors. Acta Neuropathol 116: 597-602, 2008.
3. Watanabe T, Nobusawa S, Kleihues P and Ohgaki H: IDH1 mutations are early events in the development of astrocytomas and oligodendrogliomas. Am J Pathol 174: 1149-1153, 2009.

4. Yan H, Parsons DW, Jin G, et al: IDH1 and IDH2 mutations in gliomas. N Engl J Med 360: 765-773, 2009.

5. Ichimura K: Molecular pathogenesis of IDH mutations in gliomas. Brain Tumor Pathol 29: 131-139, 2012.

6. Ramachandran $\mathrm{N}$ and Colman RF: Chemical characterization of distinct subunits of pig heart DPN-specific isocitrate dehydrogenase. J Biol Chem 255: 8859-8864, 1980.

7. Ichimura K, Pearson DM, Kocialkowski S, et al: IDH1 mutations are present in the majority of common adult gliomas but rare in primary glioblastomas. Neuro Oncol 11: 341-347, 2009.

8. Hartmann C, Hentschel B, Wick W, et al: Patients with IDH1 wild type anaplastic astrocytomas exhibit worse prognosis than IDH1-mutated glioblastomas, and IDH1 mutation status accounts for the unfavorable prognostic effect of higher age: implications for classification of gliomas. Acta Neuropathol 120: 707-718, 2010.

9. Zhao S, Lin Y, Xu W, et al: Glioma-derived mutations in IDH1 dominantly inhibit IDH1 catalytic activity and induce HIF-1 $\alpha$. Science 324: 261-265, 2009

10. Dang L, White DW, Gross S, et al: Cancer-associated IDH1 mutations produce 2-hydroxyglutarate. Nature 462: 739-744, 2009.

11. Sahm F, Capper D, Pusch S, et al: Detection of 2-hydroxyglutarate in formalin-fixed paraffin-embedded glioma specimens by gas chromatography/mass spectrometry. Brain Pathol 22: 26-31, 2012.

12. Hughes JM, Groot AJ, van der Groep P, et al: Active HIF-1 in the normal human retina. J Histochem Cytochem 58: 247-254, 2010.

13. Semenza GL: Targeting HIF-1 for cancer therapy. Nat Rev Cancer 3: 721-732, 2003.

14. Mardis ER, Ding L, Dooling DJ, et al: Recurring mutations found by sequencing an acute myeloid leukemia genome. N Engl J Med 361: 1058-1066, 2009.

15. Taylor CT: Interdependent roles for hypoxia inducible factor and nuclear factor- $\mathrm{\kappa B}$ in hypoxic inflammation. J Physiol 586: 4055-4059, 2008.

16. Walmsley SR, Farahi N, Peyssonnaux C, et al: Hypoxia-induced neutrophil survival is mediated by HIF-1 $\alpha$-dependent NF- $\kappa B$ activity. J Exp Med 201: 105-115, 2005.

17. Bruning U, Fitzpatrick SF, Frank T, et al: NFkappaB and HIF display synergistic behaviour during hypoxic inflammation. Cell Mol Life Sci 69: 1319-1329, 2012.

18. Koong AC, Chen EY and Giaccia AJ: Hypoxia causes the activation of nuclear factor kappa B through the phosphorylation of I kappa B alpha on tyrosine residues. Cancer Res 54: 1425-1430, 1994.

19. Kenneth NS and Rocha S: Regulation of gene expression by hypoxia. Biochem J 414: 19-29, 2008.

20. Cummins EP and Taylor CT: Hypoxia-responsive transcription factors. Pflugers Arch 450: 363-371, 2005.

21. Laver T, Nozell S and Benveniste EN: The NF-kB signaling pathway in GBMs: implications for apoptotic and inflammatory responses and exploitation for therapy. In: CNS Cancer, Cancer Drug Discovery and Development. Van Meir EG (ed). Springer, pp1011-1036, 2009.

22. Gilmore TD: Introduction to NF-kappaB: players, pathways, perspectives. Oncogene 25: 6680-6684, 2006.

23. Perkins ND: The Rel/NF-kappa B family: friend and foe. Trends Biochem Sci 25: 434-440, 2000.

24. Perkins ND and Gilmore TD: Good cop, bad cop: the different faces of NF-kappaB. Cell Death Differ 13: 759-772, 2006.

25. Livak KJ and Schmittgen TD: Analysis of relative gene expression data using real-time quantitative PCR and the 2(-Delta Delta C(T)) Method. Methods 25: 402-408, 2001.

26. Lee CH, Jeon YT, Kim SH and Song YS: NF-kappaB as a potential molecular target for cancer therapy. Biofactors 29: 19-35, 2007.

27. Sethi G, Sung B and Aggarwal BB: Nuclear factor-kappaB activation: from bench to bedside. Exp Biol Med (Maywood) 233: 21-31, 2008.

28. Van Waes C: Nuclear factor-kappaB in development, prevention, and therapy of cancer. Clin Cancer Res 13: 1076-1082, 2007.

29. Reitman ZJ and Yan H: Isocitrate dehydrogenase 1 and 2 mutations in cancer: alterations at a crossroads of cellular metabolism. J Natl Cancer Inst 102: 932-941, 2010.

30. Dolcet X, Llobet D, Pallares J and Matias-Guiu X: NF- $\kappa$ B in development and progression of human cancer. Virchows Arch 446: 475-482, 2005. 
31. Scortegagna M, Cataisson C, Martin RJ, et al: HIF-1alpha regulates epithelial inflammation by cell autonomous NFkappaB activation and paracrine stromal remodeling. Blood 111: 3343-3354, 2008.

32. Cockman ME, Lancaster DE, Stolze IP, et al: Posttranslational hydroxylation of ankyrin repeats in IkappaB proteins by the hypoxia-inducible factor (HIF) asparaginyl hydroxylase, factor inhibiting HIF (FIH). Proc Natl Acad Sci USA 103: 14767-14772 2006.

33. Cummins EP, Berra E, Comerford KM, et al: Prolyl hydroxylase-1 negatively regulates IkappaB kinase-beta, giving insight into hypoxia-induced NFkappaB activity. Proc Natl Acad Sci USA 103: 18154-18159, 2006.

34. Ghosh S and Karin M: Missing pieces in the NF-kappaB puzzle. Cell 109 (Suppl): S81-S96, 2002

35. Hayden MS and Ghosh S: Shared principles in NF-kappaB signaling. Cell 132: 344-362, 2008.

36. Abdullah JM, Ahmad F, Ahmad KA, et al: Molecular genetic analysis of BAX and cyclin D1 genes in patients with malignant glioma. Neurol Res 29: 239-242, 2007.

37. Arato-Ohshima T and Sawa H: Over-expression of cyclin D1 induces glioma invasion by increasing matrix metalloproteinase activity and cell motility. Int J Cancer 83: 387-392, 1999.

38. Zhang X, Zhao M, Huang AY, et al: The effect of cyclin D expression on cell proliferation in human gliomas. J Clin Neurosci 12: $166-168,2005$.
39. Liao DJ, Thakur A, Wu J, Biliran $\mathrm{H}$ and Sarkar FH: Perspectives on c-Myc, cyclin D1, and their interaction in cancer formation, progression, and response to chemotherapy. Crit Rev Oncog 13: 93-158, 2007.

40. Robson S, Pelengaris S and Khan M: c-Myc and downstream targets in the pathogenesis and treatment of cancer. Recent Pat Anticancer Drug Discov 1: 305-326, 2006.

41. Nobusawa S, Watanabe T, Kleihues P and Ohgaki H: IDH1 mutations as molecular signature and predictive factor of secondary glioblastomas. Clin Cancer Res 15: 6002-6007, 2009.

42. Houillier C, Wang X, Kaloshi G, et al: IDH1 or IDH2 mutations predict longer survival and response to temozolomide in low-grade gliomas. Neurology 75: 1560-1566, 2010.

43. SongTao Q, Lei Y, Si G, et al: IDH mutations predict longer survival and response to temozolomide in secondary glioblastoma. Cancer Sci 103: 269-273, 2012.

44. Lee SM, Koh HJ, Park DC, et al: Cytosolic NADP(+)-dependent isocitrate dehydrogenase status modulates oxidative damage to cells. Free Radic Biol Med 32: 1185-1196, 2002.

45. Rohle D, Popovici-Muller J, Palaskas N, et al: An inhibitor of mutant IDH1 delays growth and promotes differentiation of glioma cells. Science 340: 626-630, 2013. 